\title{
ORAÇÕES CONCESSIVAS INDEPENDENTES À LUZ DA GRAMÁTICA DISCURSIVO-FUNCIONAL ${ }^{1}$
}

\author{
Talita Storti GARCIA* \\ Erotilde Goreti PEZATTI*
}

- RESUMO: Este artigo investiga, à luz da Teoria da Gramática Discursivo-Funcional (HENGEVELD; MACKENZIE, 2008), a oração concessiva que não é subordinada a outras orações, ou seja, não apresenta relações sintáticas nem semânticas com orações anteriores ou posteriores, a que denominamos Concessiva Independente. O objetivo deste estudo consiste em descrever as propriedades discursivas, semânticas, morfossintáticas e prosódicas desse tipo de estrutura, mostrando que sua relevância está na construção e organização do discurso. Os resultados apontam que a Concessiva Independente funciona, no discurso, como um parêntese, que interrompe o fio discursivo, sendo, então, destacado por um contorno prosódico especial, aliado à presença de Atos Interativos. Constitui, portanto, um Movimento, a camada mais alta do Nível Interpessoal, nível que se relaciona aos aspectos pragmáticos da gramática de uma língua. O universo de investigação utilizado é o córpus Iboruna, um banco de dados que registra a variedade do português do noroeste paulista.

- PALAVRAS-CHAVE: Oração adverbial concessiva. Orações concessivas independentes. Teoria da Gramática Discursivo-Funcional. Movimento. Nível interpessoal.

\section{Introdução}

Desde os gramáticos da língua latina, tais como Bassols (1956), Scherer (1975) e Kühner e Stegmann (1914), conforme afirma Puente (1998, p.17), as relações de concessão se definem como "[...] aquelas que expressam uma objeção real ou possível ao que está sendo apresentado na oração principal."2

* UNESP - Universidade Estadual Paulista. Instituto de Biociências, Letras e Ciências Exatas - Departamento de Letras Modernas. São José do Rio Preto - SP - Brasil. 15054-000 - talita@ibilce.unesp.br

** UNESP - Universidade Estadual Paulista. Instituto de Biociências, Letras e Ciências Exatas - Departamento de Estudos Linguísticos e Literários. São José do Rio Preto - SP - Brasil. 15054-000 - pezatti@ibilce.unesp.br

1 Este artigo é resultado da Tese de Doutorado intitulada As relações concessivas no português brasileiro falado sob a perspectiva da Gramática Discursivo-Funcional, defendida na Universidade Estadual Paulista, Câmpus de São José do Rio Preto.

2 "Según Bassols (1956) y Scherer (1975), las oraciones concesivas expresan una objeción real o posible a lo dicho en la oración principal." (PUENTE, 1998, p.17). 
Em português, gramáticos como Cunha (1972), Bechara (1999) e Cunha e Cintra (2001) assumiram a mesma definição dos gramáticos latinos, pois, de modo geral, afirmam que uma oração adverbial concessiva exprime um obstáculo - real ou suposto - que não impedirá ou modificará de modo algum a declaração da oração principal, conforme mostra o exemplo de Bechara (1999, p.496). Segundo o autor, a chuva não será um obstáculo tal, que me impedirá de sair.

\section{(1) Embora chova, sairei.}

Como se pode notar, nas gramáticas, a oração concessiva se define em função de uma outra oração, a principal. Essa dependência entre ambas as orações, no entanto, não ocorre em todos os casos. Os dados desta pesquisa revelam ocorrências em que a oração concessiva não estabelece relações sintáticas com a oração anterior ou posterior, como exemplifica (2):

(2) Doc.: bom Fernando como você:::éh trabalha diretamente com a saú:::de eu queria saber qual que é a sua opinião sobre:: sobre a saúde pública né embora você trabalhe numa:: num órgão que não é público num órgão de atendimento né que não é público mas qual que é a sua opinião assim a respeito do dum paciente que chega e não tem convê:::nio como que é o tratamento mé::dico como que o médico tra::ta se tem difere::nça se num tem que que cê acha do SU::S queria que cê desse sua opinião sobre isso (AC-105-RO,372)

Em (2), a oração embora você trabalhe num órgão que não é público num órgão de atendimento que não é público não depende sintaticamente da oração anterior (eu queria saber a sua opinião sobre saúde pública) e nem da oração posterior (qual é a sua opinião a respeito de um paciente que chega e não tem convênio, como é o tratamento médico) para se estabelecer no discurso. Denominamos este tipo de Oração Concessiva Independente.

A proposta deste artigo é, pois, investigar as orações concessivas independentes no português falado no interior do Estado de São Paulo à luz da teoria da Gramática Discursivo-Funcional - doravante GDF (HENGEVELD; MACKENZIE, 2008). O objetivo consiste em descrever as propriedades discursivas, morfossintáticas e prosódicas desse tipo de estrutura.

O universo de investigação é composto pelo córpus Iboruna (GONÇALVES, 2010), um banco de dados do Projeto Alip (Amostra Linguística do Interior Paulista), que foi idealizado em 2004 pelo GPGF (Grupo de Pesquisa em Gramática Funcional) da Unesp do câmpus de São José do Rio Preto, Estado de São Paulo, Brasil, e coordenado pelo Professor Dr. Sebastião Carlos Leite Gonçalves com auxílio da FAPESP, cujo objetivo consiste em fazer um mapeamento da variedade linguística de algumas cidades do noroeste paulista localizadas próximas a São José do Rio Preto. 
Para este estudo, selecionamos os inquéritos da Amostra Censo, constituídos pelos seguintes tipos de textos: (i) Narrativa de experiência (NE); (ii) Narrativa recontada (NR); (iii) Descrição (DE); (iv) Relato de procedimento (RP) e (v) Relato de opinião (RO), todos gravados com o consentimento prévio dos informantes.

Este artigo está organizado da seguinte forma: a primeira e a segunda seções apresentam respectivamente um panorama das orações concessivas na literatura e no modelo teórico adotado como embasamento, o da GDF. A seção 3, que constitui o núcleo do trabalho, é reservada para a caracterização da oração concessiva independente, descrevendo suas propriedades discursivas, morfossintáticas e prosódicas, de acordo com a GDF; seguida, então, pelas considerações finais.

\section{As orações concessivas na literatura}

As orações concessivas, para Neves (1999), podem ser explicadas a partir de um esquema lógico-semântico. Do ponto de vista lógico, a oração subordinada é denominada (p) e a oração principal ou nuclear é chamada (q). Assim, haverá uma construção concessiva quando o evento expresso em (p) constituir uma condição suficiente para a não realização do fato/evento expresso em (q), mas (q) se realiza. Nesse mesmo sentido, König (1994) acrescenta que o falante se compromete com a verdade das duas orações, $\mathbf{p}$ e q, que geralmente são incompatíveis, daí o esquema: se 'p', então normalmente não 'q'. Segundo ele, em inglês, apresentam as seguintes propriedades formais:

(i) podem ocorrer antepostas ou pospostas à oração principal.

(ii) ao contrário dos outros tipos de adverbiais, em nenhuma língua existe advérbio interrogativo concessivo análogo a when, where, why, how, etc.

(iii) orações concessivas, diferentemente dos outros tipos de adverbiais, não podem ser o foco de um adjunto focalizado (partícula de Foco ${ }^{3}$ ), tais como: only, even, just, etc., como em Only because it is raining versus * Only although it was raining... ('somente embora estivesse chovendo...').

(iv) orações concessivas não ocorrem como foco de uma sentença clivada (* It was although it was raining that...).

(v) Orações concessivas não podem ser o foco de uma negação nem de uma interrogativa polar (Was he harassed because he was a journalist? vs Was he harassed although he was a journalist?).

3 Em português, podemos ter "muito embora", caso em que muito focaliza embora, e não a oração como um todo, o que atesta o estatuto de conjunção lexical de embora. 
Como sustentado por König (1994), todas essas propriedades das concessivas parecem ser manifestações de uma única característica: elas não podem ser focalizadas, o que, segundo Crevels (1998, p.131), "[...] pode ser indício de que as orações concessivas são menos integradas a suas orações principais do que os outros tipos de adverbiais."

Mizuno (2007), no entanto, observa que o grau de integração pode variar de acordo com o tipo de oração concessiva. Em um estudo sobre as concessivas do inglês introduzidas por although, Mizuno (2007), com base em König (1994), reconhece três tipos básicos de concessivas:

(i) Concessivas padrão: Embora João não tenha dinheiro, ele foi a um restaurante caro, em que se evoca uma relação de contraste se 'p,' então normalmente não 'q', ou seja, se ele não tem dinheiro, então ele não deve ir a um restaurante caro.

(ii) Concessiva retórica: imaginemos uma situação em que alguém está procurando um bom ator com olhos castanhos e diz: Embora certamente seja um bom ator, ele tem olhos azuis. A primeira oração 'p' é um argumento para a conclusão ' $r$ ', enquanto a segunda oração ' $q$ ' é um argumento para a conclusão oposta 'não-r' e a segunda oração apresenta um peso maior na argumentação. Em outras palavras, no exemplo dado, o conteúdo proposicional da primeira oração apoia a ideia de que o ator é adequado, enquanto o conteúdo proposicional da segunda oração apoia a conclusão oposta, e o impacto geral é que o falante não considera o ator como adequado, sendo a oração principal, em termos argumentativos, mais importante.

(iii) Concessiva de retificação: Ele é muito inteligente, embora ele diga coisas um pouco bobas. Esse tipo de concessão pode ser caracterizado, em termos de argumentação, pelo enfraquecimento da oração principal e relevância, portanto, da oração concessiva. Neste caso, segundo Mizuno (2007), a oração concessiva é menos dependente da oração principal do que os dois tipos anteriores.

Fica claro, pela classificação de Mizuno (2007), que, nas concessivas retóricas, a informação mais relevante está na oração principal e, nas concessivas de retificação, a informação mais relevante encontra-se na oração concessiva. No primeiro caso, a oração concessiva está anteposta à oração principal, que é mais relevante, enquanto no segundo caso, a oração concessiva, que é mais relevante, ocorre posposta à oração principal. Em outros termos, a oração mais relevante ocorre depois da menos relevante.

Para Crevels (1998), em espanhol, as concessivas introduzidas por aunque podem ocorrer como concessivas de retificação, servindo para sinalizar um turno inesperado no contexto discursivo. Dessa forma, podem somente seguir a oração principal, tal como ocorre em outras línguas, como o holandês e o alemão. 


\section{A Concessão na Gramática Discursivo-Funcional}

A Gramática Discursivo-Funcional (HENGEVELD; MACKENZIE, 2008), que tem suas bases na teoria da Gramática Funcional de linha holandesa (DIK, 1989, 1997a, 1997b), estrutura os níveis de análise de forma descendente; ou seja, inicia a sua organização partindo da intenção do falante, no Nível Interpessoal e, gradualmente, desce até o Nível Fonológico, passando antes pelo Representacional e Morfossintático, nessa ordem;

(i) considera o Ato Discursivo, e não a oração, como unidade básica de análise.

(ii) diferencia níveis de organização linguística: o interpessoal (relacionado à pragmática), o representacional (relacionado à semântica), o morfossintático (relacionado à morfossintaxe) e o fonológico (relacionado à fonologia), sendo todos eles de natureza puramente linguística. Os níveis Interpessoal e Representacional são responsáveis pela Formulação ${ }^{4}$ e os Níveis Morfossintático e Fonológico são responsáveis pela Codificação ${ }^{5}$.

(iii) modela a competência gramatical de um usuário da língua, representada pelo componente gramatical, ao lado de três componentes não gramaticais: conceitual, contextual e de saída. Esses três últimos interagem com o Componente Gramatical. O Componente Conceitual é o responsável pelo desenvolvimento da intenção comunicativa relevante para que ocorra o ato de fala e pelas conceitualizações associadas aos eventos extralinguísticos relevantes. O componente de Saída gera sinais acústicos ou expressões ortográficas com base na informação fornecida pelo Componente Gramatical. O Componente Contextual, por seu turno, contém uma descrição do conteúdo e da forma do discurso precedente e molda a forma sob a qual o evento da fala ocorrerá, a depender da relação social entre os participantes da conversação.

(iv) estrutura cada nível de organização linguística em camadas hierárquicas.

Essa estrutura hierárquica em níveis e camadas propicia uma explanação bastante adequada para a relação de Concessão. De acordo com Hengeveld e Mackenzie (2008), a concessão pode ocorrer entre Atos Discursivos, portanto no Nível Interpessoal, e entre conteúdos proposicionais, no Nível Representacional. Tanto uma quanto outra são codificadas morfossintática e fonologicamente.

\footnotetext{
4 A operação da Formulação envolve três processos interligados: (i) a seleção dos moldes apropriados para os níveis Interpessoal e Representacional; (ii) a inserção dos lexemas apropriados para esses moldes; (iii) a aplicação dos operadores representando as distinções gramaticais pedidas na análise subjacente da língua (HENGEVELD; MACKENZIE, 2008, p.2).

5 A operação da Codificação envolve três processos interligados: (i) a seleção dos padrões apropriados para os níveis Morfossintático e Fonológico; (ii) a inserção de morfemas gramaticais livres; (iii) a aplicação dos operadores que exercem seus papéis no processo de articulação na produção do ato de fala (HENGEVELD; MACKENZIE, 2008, p.2).
} 


\section{A Concessão do Nível Interpessoal}

O Nível Interpessoal trata dos aspectos formais da unidade linguística que reflete seu papel (da unidade linguística) na interação entre falante e ouvinte. $\mathrm{Na}$ interação, cada participante tem um objetivo em mente, que determina a estratégia adotada pelo Falante para obter o seu propósito comunicativo. $\mathrm{O}$ alcance desses propósitos comunicativos envolve dispêndio de energia, resultando assim numa série de ações governadas por uma estratégia global. Esse é, portanto, o nível da ação. Nesse nível, o nódulo mais alto representa o segmento inteiro do discurso sob análise, com várias camadas intermediárias que conduzem até aos componentes da unidade linguística individual. Cada elemento dessa estrutura hierárquica representa (ou descreve) uma ação que pode ser ela mesma internamente complexa, consistindo em ações menores distinguíveis. A hierarquia também representa crucialmente a sucessão ou curso de tempo das ações que são essenciais à realização da estratégia do falante. O sequenciamento de ações linguísticas em todas as camadas da hierarquia refletirá, portanto, a ordem das atividades estratégicas colocadas em prática pelo falante.

A maior unidade de interação pertinente para a análise gramatical, nesse nível, é denominada Movimento (M). Em termos de estatuto interpessoal, o Movimento é definido como uma contribuição autônoma para a interação em desenvolvimento. O que o caracteriza é a possibilidade de ser ou desencadear uma reação, tendo assim um efeito perlocutório (HENGEVELD; MACKENZIE, 2008).

Um Movimento pode conter um ou mais Atos Discursivos (A) combinados entre si, temporalmente ordenados (KEIZER; STADEN, 2009). A relação entre os Atos pode ser ou de dependência ou de equipolência, havendo, nesse caso, um Ato Nuclear e um Subsidiário.

Ao contrário dos Movimentos, o Ato não necessariamente impulsiona a comunicação em termos de objetivos conversacionais. Cada Ato Discursivo contém uma llocução (F), que especifica uma relação entre seus Participantes (P), o Falante (S) e o Ouvinte (A), e o Conteúdo Comunicado (C).

O Conteúdo Comunicado (C) corresponde à totalidade do que o Falante deseja evocar na sua comunicação com o Destinatário e contém um número variável de Subatos Atributivos $^{6}$ (T) e Referenciais (R). Os primeiros constituem tentativas do falante de evocar uma propriedade que se aplica a entidades; já os Referenciais são tentativas do falante de evocar um referente, ou seja, um conjunto (nulo, único ou múltiplo) de entidades.

Para este artigo, adotaremos a tradução de Ascriptive Act como Ato Atributivo. Alguns pesquisadores adotam o termo Ato adscritivo, mas entendemos que adscrição não corresponde ao sentido do termo em inglês, pois significa, em português, "acréscimo, adiantamento que se faz a algo que foi escrito" (HOUAISS, 2001). 
Como já foi mencionado, a unidade linguística, no Nível Interpessoal, desempenha papéis na interação entre falante e ouvinte. Esses papéis são analisados em termos de funções retóricas e pragmáticas. As propriedades de interações que fluem das estratégias de natureza proposital referem-se à retórica e à pragmática.

A pragmática é entendida como o estudo do modo como os falantes modelam as suas mensagens em relação às expectativas que têm do estado mental do ouvinte. Isso determina as partes de uma unidade linguística que serão apresentadas como particularmente salientes, as que serão escolhidas como ponto de partida do falante e as que serão consideradas compartilhadas pelo falante e pelo ouvinte. A influência desses aspectos sobre a estrutura das unidades linguísticas é rotulada de função pragmática: Tópico, Foco e Contraste.

A Retórica, por seu turno, está fundamentalmente relacionada aos modos pelos quais os componentes de um discurso são ordenados para a realização da estratégia comunicativa do falante, e também às propriedades formais de enunciados que influenciam o ouvinte a aceitar os propósitos do falante. Por isso, os aspectos de unidades linguísticas que refletem a estruturação global do discurso serão considerados funções retóricas que se aplicam a Atos Discursivos. Motivação, Orientação, Correção ou Concessão constituem funções retóricas que se aplicam a Atos subsidiários.

A Concessão, como função retórica, indica uma relação entre dois Atos discursivos, em que o Ato Subsidiário apresenta uma objeção real ou possível ao que está sendo apresentado no Ato Discursivo nuclear, conforme exemplificado em (3). O estatuto de Ato Discursivo é atestado pela possibilidade de inserir eu admito (que) no Ato Subsidiário, como na paráfrase em (3').

(3) hoje é a/ é a Silvia Laguna a presidente se eles for perguntado por ela se tem que vim alguma coisa pra Mirassol é lógico que vai querer porque ela quer o bem de Mirassol e como ela mesmo foi um:: tive um/ um adversário político um adver/ um:: que foi companheiro que foi o doutor Chim mas nunca que sempre que o PSDB quis mandar alguma coisa pra Mirassol a gente concordou e a gente teve junto... mesmo num tando no mesmo lado do do... da política... (AC-145-RO,253)

(3') a gente teve junto... mesmo (eu admito) num tando no mesmo lado do do... da política..

Neste caso, tanto a oração principal quanto a oração concessiva constituem Atos Discursivos, pertencendo, portanto, ao Nível Interpessoal, que se relaciona às questões pragmáticas da língua, pois lida com todos os aspectos formais da unidade linguística que refletem suas regras na interação entre falante e ouvinte, assim como os pressupostos de cada interação empregados pelo falante, de 
maneira mais ou menos consciente, como estratégia para atingir seus propósitos comunicativos.

Como principal consequência, no Nível Morfossintático, a oração que representa o Ato Subsidiário de Concessão ocorre após a oração que representa o Ato Nuclear. Dessa forma, nesse nível, a Expressão Linguística é constituída por uma oração independente e uma dependente, o que configura um caso de Cossubordinação. Já no Nível Fonológico, cada uma das orações constitui um Enunciado, uma vez que seus limites são claramente separados por uma pausa substancial, diferente da pausa que caracteriza o sintagma entonacional. É facilmente possível relacionar esse tipo de oração à que Mizuno (2007) denomina Concessiva de retificação.

\section{A Concessão do Nível Representacional}

O Nível Representacional se relaciona aos aspectos semânticos da unidade línguística, quer referentes ao modo como a língua se relaciona ao mundo extralinguístico que ela descreve, quer aos significados de unidades lexicais (semântica lexical) e unidades complexas (semântica composicional), independentemente do modo como essas unidades são usadas na comunicação. No Nível Representacional, as estruturas linguísticas são descritas em termos da denotação que fazem de uma entidade e, portanto, a diferença entre as unidades desse nível é feita em termos da categoria denotada. De acordo com a categoria, podemos reconhecer várias camadas (Conteúdo Proposicional, Episódio, Estadosde-Coisas e Propriedade). Para este estudo, no entanto, interessa apenas a camada do Conteúdo Proposicional, conforme veremos a seguir.

O Conteúdo Proposicional é a camada mais alta do Nível Representacional e constitui uma entidade de terceira ordem, ou seja, um constructo mental. Como tal não pode ser localizado no espaço nem no tempo, mas pode ser avaliado em termos de sua verdade e qualificado em termos de atitudes proposicionais (certeza, dúvida, descrença), e/ou em termos de sua origem ou fonte (conhecimento partilhado, evidência sensorial, inferência).

Por representar uma objeção real ou possível ao que está sendo apresentado, a Concessão constitui um Conteúdo Proposicional. Nesse caso, a relação Concessão é estabelecida entre dois Conteúdos Proposicionais: um representado pela oração principal e outro pela subordinada. A ocorrência (4) exemplifica esse caso.

(4) eu não gostei da/do Edinho ter ganhado a eleição só que também não gostaria que o Mané tivesse ganhado na verdade minha preferência era pro Nicolau professor Nicolau...é::eu acho/acreditava que ele era:: melhor preparado entre os dois... 
concorrentes do segundo turno...só que infelizmente quem foi pro segundo turno foi o Edinho e o:: Manuel Antunes e:::acabou ganhando o Edinho...e eu acredito que::...[apesar de não ter gostado do Edinho ganhar] [eu acredito que tenha sido melhor do que o Mané]...porque o Manuel Antunes...e/eu acho que ele não tem muita:::perspectiva como pode se dizer:.....ele já ta um pouco velho com uma certa idade e não tem muita condição mas de governar uma cidade como Rio Preto... (AC-49-RO,145)

Em (4), a oração concessiva apesar de não ter gostado do Edinho ganhar constitui um Conteúdo Proposicional que restringe o Conteúdo Proposicional expresso na principal eu acredito que tenha sido melhor do que o Mané, ao indicar uma atitude especificando o grau de comprometimento de um ser racional com o Conteúdo Proposicional. Nesse caso, não é permitida a inserção de eu admito (que) ${ }^{7}$, conforme demonstra a paráfrase em (4').

(4') *apesar de (eu admito) não ter gostado do Edinho ganhar eu acredito que tenha sido melhor do que o Mané...

Em outros termos, a Concessiva do Nível Representacional constitui um modificador do núcleo representado pela principal; o que caracteriza, no Nível Morfossintático, uma Subordinação. Isso se reflete na ordenação dessas orações dentro da Expressão Linguística: a oração subordinada assume a posição anterior à principal. Essas propriedades também se refletem no Nível Fonológico, já que cada uma constitui um Sintagma Entonacional e, juntas, um único Enunciado. Esse tipo de estrutura é denominado por Mizuno (2007) Concessiva Retórica.

\section{A oração Concessiva Independente}

Nos dois casos apresentados anteriormente, há uma relação de dependência entre as orações envolvidas. Em outras palavras, a oração concessiva é um constituinte da oração principal, uma vez que a restringe, sendo, portanto, um modificador.

Os dados do português falado no interior paulista revelam, entretanto, um tipo de concessão não previsto pela Gramática Discursivo-Funcional. Trata-se de orações concessivas que expressam um comentário do falante com relação ao contexto, sem se prender a uma oração principal. A essas construções denominamos Orações Concessivas Independentes, conforme exemplifica (5).

A inserção "eu admito (que)" deve ser lida sem pausa. Caso "eu admito (que)" seja lido com pausas, terá, consequentemente, contorno entonacional próprio e essa interposição poderia ser gramatical em português. 
(5) Inf: éh:: outra coisa... importante em aula particular é você cair especificamente na dúvida dele... às vezes... ele:: chega um aluno às vezes ele fala - "eu não entendi essa matéria" - mas aí ce vendo ce fazendo com ele ce percebe que às vezes o problema não é da matéria o problema é de outra coisa anterior à matemática às vezes ele chega... ah:: a gente tem aluno hoje apesar que melhorou um pouco mas antigamente tinha menos pior ainda às vezes ele não sabe fazer conta... (AC-81-RP,205)

A ocorrência (5) mostra que a oração concessiva apesar que melhorou um pouco não depende sintática e nem semanticamente da oração anterior [a gente tem aluno hoje] e nem da oração posterior [antigamente tinha menos pior ainda]. Ela sozinha expressa um comentário do falante com relação ao conteúdo apresentado. Diferentemente das concessivas tratadas anteriormente, não se subordinam a Atos Discursivos nucleares, mas constituem uma unidade de informação à parte. Esse tipo de estrutura é responsável por 40\% das ocorrências em nossos dados, o que configura tratar-se de casos muito frequentes no português falado nessa região do estado de São Paulo.

Essas estruturas concessivas facilmente podem ser relacionadas às que Crevels (2000) denomina Concessivas Textuais. A relação existente nesse tipo de estrutura é apenas pragmática, ou melhor, interpessoal, pois o falante considera pertinente informar ao ouvinte o conteúdo comunicado na oração concessiva e assim a insere no discurso como um parêntese. Essa propriedade leva Decat (1999, 2001) a denominá-las "desgarradas", já que a relação de dependência mostra-se frouxa, originando um "desgarramento", já que as orações não são integradas estruturalmente em outras.

O desgarramento das orações concessivas não é um fenômeno só do português do Brasil. Günthner (2000), em um estudo das orações concessivas do alemão coloquial introduzidas por obwohl, afirma que há concessivas que não apresentam integração sintática, o que altera o estatuto de obwohl de conjunção para marcador discursivo (que deve ser entendido aqui apenas como marcador no nível discursivo). Para Günthner (2000), as orações concessivas sem integração sintática são usadas pelo falante para limitar ou corrigir a validade das asserções precedentes no discurso. Corrigir é entendido pela autora como autocorreção, como se o falante dissesse "sou contra o que eu acabei de dizer"8. Na verdade, trata-se de uma estratégia de preservação da face ${ }^{9}$.

8 "The meaning of this corrective use of obwohl is somewhat loke 'as against what I just said', and thus corresponds to what Halliday/Hasas (1976) call the 'corrective type' among 'adversative relations'." (GÜNTHNER, 2000, p.445)

9 "Corrective obwohl is not restrict to self-correction but can also be used as a dissent marker by a second speaker to frame an upcoming disagreement. The obwohl-construction refutes the preceding utterance and prevides a partially or totally contractitory second assessment. It reads something like: "As against what you just said". A plausive explanation seems to be that obwohl does not articule an explicit, "on 
Com base nos estudos de Barth (2000) sobre as funções das concessivas do inglês, do ponto de vista discursivo-organizacional, postulamos aqui que as concessivas independentes apresentam a função de introduzir informações adicionais, não para restringir o conteúdo da primeira oração, conforme afirma Barth (2000), mas para permitir ao falante a "preservação da face", já que não há uma oração a ser tomada como escopo, como demonstra a ocorrência (6):

(6) Doc.: problema básico né?[(inint.)]

Inf: [então ele] chega LÁ numa calculadora ele acerta tudo só que na prova não vai ter calculadora né? então a gente:: infelizmente tem que tomar a calculadora apesar de eu ser até favorá::vel né? ao uso de calculadora de/ de repente numa prova dependendo da prova né? então:: tem que ensinar conta prá ele (AC-81$\mathrm{RP}, 209)$

Nessa ocorrência, o Falante interrompe o fio discursivo, sobre o uso de calculadora, por meio da inserção da oração concessiva que introduz uma ideia contrária à apresentada, ou seja, o Falante acrescenta uma informação de ser favorável ao uso em algumas situações, para prevenir objeções do tipo "[...] como alguém é contra o uso da calculadora e, por extensão, da tecnologia, em pleno século XXI?", ou questionamentos semelhantes.

A preservação da face, de acordo com Goffman (1967), é uma estratégia usada pelo falante para que sua conduta ou a conduta de outra pessoa seja mantida dentro dos padrões sociais estabelecidos por uma cultura.

Há, no entanto, casos em que as orações concessivas independentes simplesmente acrescentam uma informação, em geral contrária à anterior, apenas como uma observação, conforme comprova a ocorrência (7):

(7) eu acho que esse negócio de droga / esse negócio da/a/as pessoa::: ... mais pobre é as que sofre mais:.... SOFRE MAIS sofre mais eles num vai ... nos bai::le ... ver como que tá:......eles num dá uma assistên::cia ... nenhuma ... esse ... Edinho - que é o prefeito de Rio Preto - é uma por.::caria: ... eu:: n/ não votei ne::le ... eu votei no Mané... ... e eu num sei: ... apesar que é tudo uma porcaria.: né? ... mas eu acho que o Mané ia ser ... um pouco (menos ruim) que ele: ... por que eu acho que o Edinho num sabe fazer NADA: ... nada nada nada:.... ele só que::r ir lá pra Brasília:: bem.: ... só que ir pra Brasí::lia ... pra ter o de:.le ... pra tirar o dele: ... (AC-62-RO,393)

Como já deve ter ficado claro, a relação concessiva, objeto deste estudo, pertence ao Nível Interpessoal, uma vez que atua na interação Falante-Ouvinte,

record", dissent, but a weakened and more face-saving form of indicating an upcoming disagreement." (GÜNTHNER, 2000, p.445). 
mais especificamente na organização discursiva. Conforme mostra Stassi-Sé (2012), esse tipo de oração concessiva constitui um Movimento. Com base em Kroon (1997), que define Movimento como "a menor unidade livre do discurso" 10 capaz de participar em uma estrutura de interação, Hengeveld e Mackenzie (2008, p.50) o definem como "[...] uma contribuição autônoma para a interação contínua ${ }^{11 .}$.", uma vez que constitui uma ação ou movimento para introduzir ou modificar tópicos discursivos e levar a interação adiante. Essa contribuição autônoma para a interação em desenvolvimento é claramente marcada.

Uma das marcas que caracteriza a oração concessiva independente é a presença da conjunção mas introduzindo a oração que a segue, conforme se observa em (8).

(8) Inf.: mas assim foi ótimo... viajei de madrugada porque a passagem... era mais barata né?

Doc: : aham

Inf:: e:: num tive receio algum:: éh:.... o serviço de bordo foi muito bom... sabe? embora fosse.: éh:: assim a passagem assim mais econômica né? ${ }^{3}[. .$.$] mas foi$ tudo legal (AC-134-NE,16)

Nessa ocorrência, o falante inicia dizendo algo positivo a respeito da viagem (o serviço de bordo foi bom) e segue fazendo uma interrupção para ressaltar algo que poderia contrariar essa ideia (embora fosse a passagem mais econômica), retomando depois a ideia de que tudo foi muito bom com a oração introduzida por mas (mas foi tudo legal), cuja função é indicar a retomada do fio discursivo, interrompido devido à inserção da oração concessiva.

Essa função de retomada do fio narrativo também pode ser marcada por então, conforme podemos observar em (9), com a oração então na verdade a gente quando dá aula particular a gente tem que ser... o mais próximo da realidade do aluno que segue a oração concessiva apesar de que na escola que eu dou aula........ noventa e nove por cento dos alunos não tem problema nenhum de capacidade a maioria é falta de estudo é:: que não está se adaptando à escola.

(9) Inf: também mas eu acho que daí acho que professor é também... ele pode contornar isso porque o professor SAbe dando a matéria onde que o aluno vai ter dúvida lógico que nem todo aluno vai ter a mesma dúvida mas:: ele pode dar ênfase em alguma coisa em:: determinado assunto né?

Doc.: uhum ((concordando))

10 Minimal free unit of discourse (KROON, 1997).

11 "A Move may be defined as an autonomous contribution to an ongoing interaction." (HENGEVELD; MACKENZIE, 2008, p.50). 
Inf: então então esse aluno chega lá com a gen::te ele ele tá:: inibido né? Então às vezes até é um problema que ele tem mais:: psicológico do que:: ne? apesar de que a escola que eu dou aula é uma escola de:: éh reFORço:: noventa e nove por cento dos alunos não tem problema nenhum de capacidade a maioria é falta de estudo é:: que não está se adaptando à escola então na verdade a gente quando dá aula particular a gente tem que ser... o mais próximo da realidade do aluno possível e ver o que ele MAIS tem dúvida o que:: é a sua defasagem e às vezes nem é uma defasagem é um aprimoramento é prá ele ser melhor por exemplo aluno de cursinho não basta ser bom tem que ser o melhor (AC-81-RP,237)

A oração concessiva constitui, portanto, uma inserção no discurso, para introduzir uma informação considerada importante pelo falante. A teoria da Gramática Textual-Interativa (JUBRAN; KOCH, 2006), denomina esse tipo de inserção de Parêntese, ou seja, uma modalidade de inserção " [...] definida como breves desvios de um tópico ${ }^{12}$ discursivo, que não afetam a coesão do segmento tópico dentro do qual ocorrem." (JUBRAN, 2006, p.303).

Os parênteses, ainda de acordo com Jubran (2006), apresentam uma dimensão pragmática, pois eles materializam a atividade interacional no texto falado, contextualizando-o na situação de enunciação. Dessa forma, esses parênteses introduzem dados relacionados à dimensão pragmática, e podem ser constituídos por marcadores discursivos, como né, que o encaminha para uma perda de transparência semântica. As orações que aparecem após os parênteses, por sua vez, podem apresentar várias marcas de reintrodução do tópico discursivo, como: (i) uso de conectivos ou de pronomes que atam a oração posterior à anterior ao parêntese; (ii) uso de Atos Interativos sequenciadores do tópico; (iii) repetição de itens lexicais ou de sintagmas do segmento-contexto, que se encontram próximos ao início do parêntese e, por último, (iv) parafraseamento de trechos precedentes ao parêntese.

O parêntese efetuado pela Concessiva tipicamente apresenta todas essas marcas. Como já observado, os conectivos mas e então são comumente usados para atar a oração que antecede à que segue o parêntese Concessivo (cf. (8) e (9)).

É também muito frequente a ocorrência de Atos Interativos, como sabe?, né ${ }^{13}$, antecedendo ou fechando o parêntese Concessivo. Em (8), apresentada

12 A noção de Tópico discursivo para a Teoria da Gramática Textual-Interativa é uma unidade de análise que não está restrita aos turnos conversacionais. Decorre de um processo que envolve colaborativamente os participantes do ato interacional na construção da conversação, assentada em um complexo de fatores contextuais, entre os quais as circunstâncias em que ocorre o intercâmbio verbal, o grau de conhecimento recíproco dos interlocutores, os conhecimentos partilhados entre eles, sua visão de mundo, o background de cada um em relação ao que falam. Assim, o tópico discursivo "[...] torna-se um elemento decisivo na constituição de um texto falado, e a estruturação tópica serve como fio condutor da organização textualinterativa." (JUBRAN, 2006, p.90).

13 Segundo Urbano (2006), né? parece ter origem na forma matriz não é verdade? e ter feito o seguinte percurso: Isso não é verdade? > Não é verdade? > Não é? > Né?. Esses Atos interativos desempenham a mesma 
anteriormente, a oração concessiva embora fosse a passagem mais econômica é antecedida pelo Ato Interativo sabe? e seguida pelo Ato Interativo né?.

Além disso, observa-se a repetição de itens lexicais ou paráfrases de estruturas depois da oração concessiva, marcando a retomada do fio discursivo (cf. (10)).

(10) Doc.: Soeli... cê pode contar prá gente agora descrever... um local?...

Inf: posso... a casa da minha amiga filó... ((doc.: uhm)) muito linda a casa dela no Recanto Real... ((doc.: uhm)) [apesar de ela né? não tá... bem ] mas... o lugar onde ela convive é muito lindo... um paraíso aquilo lá... ((doc.: uhm sei)) eu entrei na casa não sabia sair... ((risos))

Doc.: ahm... ${ }^{1}$ [enorme]

Inf.: de tão ${ }^{1}$ [grande...] de tão enorme que era... é muito bonito lá sabe... (AC-90$\mathrm{DE}, 222)$

Em (10), o trecho que antecede a oração concessiva muito linda a casa dela no Recanto Real é retomado após a oração concessiva por meio da paráfrase o lugar onde ela convive é muito lindo. Podemos dizer que o fio discursivo é interrompido pela oração concessiva apesar de ela não né? não tá...bem e depois retomado. Essa retomada é marcada por meio de mas e de uma paráfrase.

Essas marcas comprovam a independência desse tipo de estrutura concessiva e lhe atribuem o estatuto de parêntese discursivo, ou seja, uma unidade de informação à parte no discurso.

\section{Propriedades morfossintáticas das concessivas}

As orações concessivas independentes, conforme já explicado, não fazem referência a nenhuma oração anterior ou posterior, isto é, não apresentam relação de dependência sintática com a oração principal, como fazem as concessivas do Nível Representacional, que constituem morfossintaticamente casos de subordinação, pois consistem em um modificador da oração principal. Diferem também das concessivas de Ato, que constituem casos de cossubordinação, já que se relaciona a uma oração independente dentro de uma mesma Expressão Linguística. As concessivas independentes morfossintaticamente correspondem a Expressões Linguísticas (Le), já que constituem uma unidade que pode ser usada independentemente, sem fazer parte de outra unidade. Isso não impede, entretanto, a sua caracterização morfossintática.

função básica: a fática e são comparáveis às chamadas "questions tag". Quando o falante faz uso desses elementos, busca aprovação discursiva do ouvinte, sendo, portanto, basicamente interacionais. 
Tal como as concessivas não integradas do alemão (GÜNTHNER, 2000), as orações concessivas independentes tendem a apresentar (51\%) o verbo na forma finita, no modo indicativo, conforme exemplifica a ocorrência (11).

(11) Doc.: E a praia lá é limpi:nha? Te:m tem muito ba:r ...? muita/ muito lugar assi:m ... de diversão?

Inf.: ai: é num TEM NÃO viu:: ... fo/ apesar que mudou MUI::TO ... nu/é/ antigamente num tinha quiosque.:. ... eles fizeram quiosque no...:vo: ... tem/ tem bastante: quiosque no::vo ... boniti::nho: tem só um ba:r lá ... um ba:::r qu/qu/tem ... é ... mesa de sinu::ca::... essa coisa... mas a gente:/mas é /levo né? de casa ... levou cerve::.ja no isopo:r ... o que tinha que comprar lá/ o que a gente comprou foi ge:lo né? ... agora/ é/ a água ... é:: água de prainha não é muito limpi:.nha não:: né? (AC-62-DE,279)

A predominância do uso do indicativo constitui um forte indício para a independência desse tipo de oração. Há casos, no entanto, em que se observa a ocorrência do subjuntivo (23\%), conforme exemplificado pela ocorrência (12), sendo ainda possíveis formas verbais não finitas (26\%), como mostra (13).

(12) Inf. então ele mostrou QUE... vale muito mais o conhecimento que uma pessoa tem do que a atitude que ela vai tomar... às vezes a atitude pode ser muito SIMples... mas pra ela cheGAR... a tomar aquela atitude muito simples [ela tem que ter tido MUI:.to conhecimen::to... MUIto esTUdo... e.: mesmo que num seja estudo em faculda:: de... estudo em em em esCO::la... coisa por exemplo que eu num TIve... mas quando a pessoa quer alguma coisa... ela tem que correr atrás... e estudar aQUEle segmento que ela QUER...

Doc.: e valoriZAR né?... (AC-99-NR,176)

(13) Doc.: ((risos)) tem alguma outra história que tenha acontecido com o senhor?

Inf: olha isso já é um fato ocorrido no trabalho já... adulto né? apesar de ter outras passagem anterior né?... e eu no serviço que eu trabalhava até de carro-forte a gente:: viajava né? (AC-103-NE,16)

O uso dessas diferentes formas verbais (infinitivo, indicativo e subjuntivo) está relacionado à conjunção escolhida pelos falantes para a expressão da concessão: apesar de, apesar (de) que, embora, mesmo e mesmo que; sendo as mais recorrentes apesar de, apesar que e embora.

A conjunção apesar que exige o verbo no indicativo, enquanto apesar de desencadeia o uso do infinitivo. A conjunção embora, contrariando o que postulam as normas gramaticais do português, que preconizam o uso de verbos no subjuntivo, pode tanto ser seguida de verbos no indicativo, como (14), quanto no subjuntivo, como (15). O uso do indicativo, nesses casos, parece estar ligado ao grau de dessentencialização desse tipo de concessiva: 
(14) Inf.: é uma coisa que foi muito marcante prá MIM foi que eu conheci o pai dos meus filhos eu tinha mais ou menos uns quatorze prá quinze anos ${ }^{1}$ [né?] a gente namoro::u durante um a::no... e:: a gente eu peguei engravidei dele né? não FOI um uma gravidez deseJADA mas aconteceu a gente encarou a gravidez né?... ham:: eh:: eh:: fiquei:: tive a gestação perfei::ta né? meus pais embora não aceitaram MUI::to né? mas eles impuseram a condição de que eu fosse morar com ele ou casar... (AC-40-NE,10)

(15) Doc.: bom Fernando como você::: éh trabalha diretamente com a saú::de eu queria saber qual que é a sua opinião sobre:: sobre a saúde pública né embora você trabalhe numa:: num órgão que não é público num órgão de atendimento né que não é público mas qual que é a usa opinião assim a respeito do dum paciente que chega e não tem convê::nio como que é o tratamento mé::dico como que o médico tra::ta se tem difere::nça se num tem que que cê acha do SU::S queria que cê desse sua opinião sobre isso (AC-105-RO,372)

\section{Propriedades prosódicas das concessivas independentes}

O Nível Fonológico está organizado com base em padrões fonológicos para o Enunciado, Sintagma Entonacional, Sintagma Fonológico, Palavra Fonológica, Pé e Sílaba, que ficam estocados como parte do conjunto de primitivos relevantes para a operação de Codificação Fonológica (HENGEVELD; MACKENZIE, 2008).

Günthner (2000) constata que as orações não integradas introduzidas por obwohl no alemão coloquial apresentam contorno entonacional próprio e são separadas por pausas de aproximadamente 0,5 segundo. No português também é possível observar, nessas orações independentes, pausas que as separam das orações anteriores e posteriores e um contorno entonacional próprio.

Além das pausas nas fronteiras dessas orações e do contorno entonacional próprio, pode-se observar mudança na tessitura, o que confere a essas orações a estrutura de uma inserção parentética, com força ilocucionária própria. Isso pode ser observado na ocorrência (16) que apresenta pausas antes e depois da oração independente a minha mulher é candidata a vereadora né?

(16) Doc.: ham:: tá... e assim éh o senhor sabe que agente tá em época de eleiçã::0 ${ }^{1}[$ né]? éh... o direit/as eleições... estão a/ muito pró::ximas a menos de um MÊS que que o senhor acha da política de atualmente ${ }^{2}[($ dos políticos)]

Inf:: [sei] ['éh eu] num sou FÃ... de política... num é? apesar que a minha mulher é candidata a vereadora né?... MAS... se ela quis tomar ela tomou a iniciativa de ser... né? eu resPEIto eu acomPANho e tudo bem MAS... política prá mim é uma coisa muito suja...((ouve-se interferências vindas de fora)) então prá mim num tem $(\mathrm{AC}-111-\mathrm{RO}, 417)$ 
Um estudo prosódico dos parênteses, realizado por Tenani (1997), revela que neles tende a coocorrer aumento da velocidade da fala e mudança de tessitura (geralmente mais baixa ou mais alta do que as porções textuais anteriores e posteriores, conforme já mencionado). Também pode-se notar a mudança na direção da altura da sílaba final acentuada (uma curva descendente, em geral) e ocorrências das pausas, o que assinala a formação de um grupo entonacional (TENANI, 1997). Em outros termos, essas orações constituem Enunciados (Utterances). Um Enunciado, de acordo com Hengeveld e Mackenzie (2008), é caracterizado por ter seus limites claramente separados por uma pausa substancial, diferente da pausa que caracteriza o sintagma entonacional.

\section{Considerações finais}

Este estudo mostra que, no português falado no interior paulista, há um tipo de oração concessiva que foge às concessivas prototípicas apontadas pela tradição gramatical.

De acordo com Hengeveld e Mackenzie (2008), o falante, para ser compreendido, não expressa nada além de sua intenção comunicativa. Assim, a introdução de uma oração concessiva independente ocorre quando o falante julga que a concessão é relevante do ponto de vista informacional, pois pode tanto indicar uma ação de preservação da face quanto uma ação de simples observação.

Tendo em vista a organização em Níveis e camadas da Gramática DiscursivoFuncional, as concessivas independentes constituem uma contribuição autônoma para a interação contínua. Em outras palavras, constituem um Movimento, a camada mais alta do Nível Interpessoal. Como tal pode abrir uma possibilidade de reação no interlocutor, tendo, inclusive, um efeito perlocucionário, conforme ilustra (17), em que a oração concessiva inserida apesar que acho que você já deve ter ouvido muita história de amante poderia causar uma resposta positiva no documentador, do tipo "sim, já ouvi, por isso conte uma outra história".

(17) Inf.: eu tenho um tio... ((doc.: uhum...)) sabe ele era fazende:.iro rico tal... e ele teve uma amante... sabe?... apesar que acho que cê/ você já deve ter ouvido muita história de amante... ((doc.: uhum)) mas essa que eu vi é diferente... eu sei que:.... ele era mulherengo tudo ela inclusive minha tia acho que largou... dele foi exatamente por causa disso... (AC-100-NR,109)

Esse tipo de estrutura constitui, na verdade, breves desvios de um tópico discursivo, que não afetam a coesão do segmento tópico dentro do qual ocorrem, por isso é denominado de Parêntese na teoria da Gramática Textual-Interativa (JUBRAN; KOCH, 2006). Como parêntese, caracteriza-se por não estar atado a uma 
oração principal e ser destacado do contexto circundante por claras pausas e Atos Interativos, bem como por apresentar um contorno entonacional próprio. Além disso, a retomada do fio discursivo, interrompido pela concessiva, é efetuada por meio de conjunções como mas e então, e por meio de repetições ou paráfrases da estrutura interrompida.

Apesar da independência morfossintática e fonológica, essas estruturas mostram-se de extrema importância do ponto de vista interacional, pois representam uma contribuição autônoma para a interação contínua, permitindo ao Falante ora preservar a sua face ou a de outrem, ora simplesmente acrescentar uma observação.

GARCIA, T. S.; PEZATTI, E. G. Independent concessive clauses in the light of Functional Discourse Grammar. Alfa, São Paulo, v.57, n.1, p.475-494, 2013.

- ABSTRACT: This paper investigates, in light of the theory of Functional Discourse Grammar (HENGEVELD; MACKENZIE, 2008), the concessive clause that is not subordinated to other clauses, i.e., it has no semantic or syntactic relations with clauses before or after it, and which we call Independent Concessive. The aim is to describe the discursive properties and the semantic, morphosyntactic and prosodic structure of this type of clause, showing that its relevance is in the construction and organization of discourse. The results indicate that the Independent Concessive works in speech as a parenthesis which interrupts the discursive course and is then highlighted by a special prosodic contour, combined with the presence of Interactive Acts. It is therefore a Move, the highest layer of the Interpersonal Level, the level that relates to the pragmatic aspects of the grammar of a language. The universe of research used is the Iboruna corpus, a database that records a variety of Portuguese from the Northwest of São Paulo.

- KEYWORDS: Concessive adverbial clause. Independent concessive clause. Functional Discourse Grammar Theory. Moves. Interpersonal level.

\section{REFERÊNCIAS}

BARTH, D. "That's true, although not really, but still": expressing concession in spoken English. In: COUPER-KUHLEN, E.; KORTMANN, B. (Ed.). Cause, condition, concession, contrast cognitive and discourse perspectives. Berlin: Mounton de Gruyter, 2000. p.411-437.

BASSOLS, M. Sintaxis Latina. Madrid: Consejo Superior de Investigaciones Científicas, 1956.

BECHARA, E. N. Moderna gramática da língua portuguesa. 37.ed. Rio de Janeiro: Lucerna, 1999.

CREVELS, M . Concession: a typological study. 2000. 191 f. Tese (Doutorado) University of Amsterdam, Amsterdam, 2000. 
Concession in spanish. In: HANNAY, M.; BOLKESTEIN, A. M. (Ed.). Functional grammar and verbal interaction. Amsterdam: John Benjamins, 1998. p.129-148.

CUNHA, C. F. Gramática do português contemporâneo. 3.ed. Belo Horizonte: Bernardo Álvares, 1972.

CUNHA, C.; CINTRA, L. Nova gramática do português contemporâneo. 3.ed. Rio de Janeiro: Nova Fronteira, 2001.

DECAT, M. B. N. Orações adjetivas explicativas no português brasileiro e no português europeu: aposição rumo ao "desgarramento". SCRIPTA, Belo Horizonte, v.5, n.9, p.104-118, jul./dez. 2001.

Por uma abordagem da (in)dependência de cláusulas à luz da noção de "unidade informacional". SCRIPTA, Belo Horizonte, v.2, n.4, p.23-38, jan./jun. 1999.

DIK, S. C. The theory of functional grammar. the structure of the clause. New York: Mounton de Gruyter, 1997a. pt.1.

The theory of functional grammar. complex and derived constructions. New York: Mouton de Gruyter, 1997b.pt.2.

The theory of functional grammar. the structure of the clause. Dordrecht: Foris Publications, 1989. pt.1.

GOFFMAN, E. Interaction ritual: essays on face-to-face behavior. New York: Anchor Books, 1967.

GONÇALVES, S. C. L. G. Banco de dados Iboruna: amostras eletrônicas do português falado no interior paulista. Disponível em: <http:://www.iboruna.ibilce. unesp.br>. Acesso em: 21 mar. 2010.

GÜNTHNER, S. From concessive connector to discourse marker: the use of obwohl in everyday german interaction. In: COUPER-KUHLEN, E.; KORTMANN, B. (Ed.). Cause, condition, concession, contrast cognitive and discourse perspectives. Berlin: Mounton de Gruyter, 2000. p.339-468.

HENGEVELD, K.; MACKENZIE, J. L. Functional discourse grammar. a typologicallybased theory of language structure. Oxford: University Press, 2008.

HOUAISS, A. (Ed.). Dicionário Houaiss da língua portuguesa. Rio de Janeiro: Objetiva, 2001.

JUBRAN, C. C. A. S. Parentetização. In: JUBRAN, C. C. A. S.; KOCH, I. G. V. (Org.). Gramática do português culto falado no Brasil. Campinas: Ed. da UNICAMP, 2006. v.1. p.301-357.

JUBRAN, C. C. A. S.; KOCH, I. G. V. (Org.). Gramática do português culto falado no Brasil. Campinas: Ed. da UNICAMP, 2006. v.1. 
KEIZER, E.; STADEN, M. V. Interpersonal grammar: a cross-linguistic perspective. Special Issue of Linguistics, Berlin, v.47, n.4, p.799-824, jul. 2009.

KÖNIG, E. Concessive clauses. In: ASHER, R. E. (Ed.). The encyclopedia of language and linguistics. Oxford: Pergamon, 1994. v.2. p.679-681.

KÜHNER, R.; STEGMANN, C. Ausführliche Grammatik der lateinischen Sprache. Hannover: Leverkusen Gottschalksche Verlagsbuchhandlung, 1914.

KROON, C. Discourse markers, discourse structure and functional grammar. In: CONOLLY, H. J. (Ed.). Discourse and pragmatics in functional grammar. New York: Mounton de Gruyter, 1997. p.17-32.

MIZUNO,Y. Although clauses in English discourse: a functional analysis. 2007. 194 f. Tese (Doutorado) - The Graduate School of Letters, Universidade de Hokkaido, Sapporo, 2007.

NEVES, M. H. M. As construções concessivas. In: NEVES, M. H. M. Gramática do português falado. Campinas: Ed. Da UNICAMP, 1999. v.7. p.545-591.

PUENTE, C. M. La expresión de la concesividad en latín clásico: su análisis y distribución sintáctica. 1998. 371 f. Tese (Doutorado em Filologia Latina) - Facultad de Filología, Universidad Complutense de Madrid, Madrid, 1998.

SCHERER, A. Handbuch der lateinischen syntax. Heidelberg: Universitätsverlag Winter Heidelberg, 1975.

STASSI-SÉ, J. C. Subordinação discursiva no português à luz da gramática discursivo -funcional. 2012. 194f. Tese (Doutorado em Estudos Linguísticos) Instituto de Biociências, Letras e Ciências Exatas, Universidade Estadual Paulista, São José do Rio Preto, 2012.

TENANI, L. E. O fenômeno da parentetização na fala. Caderno de Estudos Lingüísticos, São Paulo, v.26, p.787-793, 1997.

URBANO, H. Marcadores discursivos basicamente interacionais. In: JUBRAN, C. C. A. S.; KOCH, I. G. V. Gramática do português culto falado no Brasil. Campinas: Ed. da UNICAMP, 2006. v.1. p.497-527.

Recebido em agosto de 2012

Aprovado em dezembro de 2012 